\title{
Politics proves its worth
}

\author{
The European Parliament has reaffirmed its legislative value by reversing the potentially disruptive \\ restrictions in the draft directive for protecting laboratory animals.
}

$\mathrm{R}$ aise a glass to the elected members of the European Parliament (MEPs). Without their intervention last week, the European Union (EU) directive on the protection of laboratory animals would have continued its tortured path through legislative procedures in a form that was thoroughly toxic to biomedical research.

The European Commission, the EU's executive arm, began working on the directive back in 2002. The draft that finally emerged last November was singularly uninformed. It should have balanced the undisputed duty to protect animals with the needs of biomedical researchers to understand disease and develop innovative therapies. Instead, it proposed restrictions that would have blocked whole areas of fundamental research while having no positive influence on animal welfare. In particular, it would have restricted research on non-human primates to "life-threatening or debilitating diseases" (which it did not define) without thought for the basic research required to understand such diseases biologically.

The draft would also have forbidden the reuse of animals in any procedure that could cause more than a "mild" (again, undefined) level of suffering. This would have ruled out the use of surgically implanted telemetric devices, which continuously monitor physiological aspects such as blood pressure or heart rate, save animals the stress of frequent handling, and allow for the testing of different compounds on a single animal. As surgery could hardly be classified as "mild", an animal would have to be killed after just a single test.

Justifiably alarmed, researchers (and Nature, see 456, 281-282; 2008) added their voices to the powerful lobby of the European drug industry - and MEPs responded. In last week's vote, the European Parliament reversed most of the problematic clauses.

So why did things go so wrong at the commission? The legislation was handled in its environment directorate, which initially consulted with all the stake-holders, but then shut itself off from all influences except the powerful animal-welfare lobby. It even failed to consult on the text with the research directorate. Then, when the text was at last opened to the entire commission for comment last summer, there was little time to make substantial changes.

In parliament, by contrast, the procedure was transparent and professional. The draft directive was examined by three committees - agriculture, research and environment - which considered the interests of animal welfare and researchers with appropriate balance.

The process is far from over, however. According to Europe's elaborate co-decision process, not only the parliament, which is directly elected every five years, but also the European Council of Ministers, comprising representatives of each of the EU's 27 member states, must agree on the final text in two readings. The council will start work on the amended text during the Swedish presidency, which begins in July. The commission will then redraft the directive, taking into account the wishes of parliament and council before the second reading. Changes can be introduced at any stage. But in the final directive, which is likely to be approved during 2011, the interests of research will not be as neglected as they were at the outset.

The European Parliament is the only one of the three EU bodies that is elected and therefore directly answerable to EU citizens. This example shows how important it is to have research-savvy MEPs. The next election takes place early next month. Scientists in the EU would be well advised to consider their local candidates' attitude towards science and to cast their vote accordingly. Meanwhile, researchers and their organizations should keep their eye on the passage of the directive, and keep their campaign weaponry close at hand.

\section{Bracing for the unknown}

Last year's earthquake in China is a salutary reminder about preparing for risk in the face of uncertainty.

$\square$ espite a century of research into earthquakes, Earth scientists are still only beginning to understand how individual faults behave. Although many dangerous faults have been identified, which has helped countries to strengthen their infrastructure, a significant number of deadly earthquakes occur on faults that are either unknown or were not thought to be particularly dangerous. That knowledge gap was highlighted last year, when a group of faults not particularly high on China's list of hazards linked together in an unexpected manner to spawn one of the most deadly quakes in recorded history, claiming at least 70,000 lives in Sichuan province (see page 153).
Earthquakes clearly pose the problem of how to prepare for risk in the face of uncertainty. The answer is complex, but can be boiled down to a few fundamental principles that scientists and government leaders should take to heart. Develop a clear message about what is known and - just as importantly - what is unknown. Be forthcoming about mistakes. And use a broad set of tools to prepare for hazards - a strategy that will make communities more resilient to different kinds of threat.

Scientists must rigorously assess the limits of their knowledge and communicate them to officials and the public. Earthquake researchers in some regions are getting better at this. California, for example, is one of the best-studied regions in terms of seismic risk. Two decades ago, seismologists there began issuing semi-regular reports on the major threats. Early on, they adopted a relatively rigid approach based on the understanding that segments of the San Andreas fault tended to behave in certain set ways, with characteristically sized earthquakes. But over time, the data — and the reports based on them 